\title{
Assessing fertilizer use efficiency and its determinants for apple production in
} China

\author{
Xiuguang Baia*, Yanan Wang ${ }^{a}$, Xuexi Huo ${ }^{a}$, Ruhul Salim ${ }^{b}$, Harry Bloch ${ }^{b}$, Han Zhang ${ }^{a}$ \\ ${ }^{a}$ College of economics \&management, Northwest A\&F University, Yangling 712100, China \\ ${ }^{\mathrm{b}}$ School of Economics \& Finance, Curtin Business School, Curtin University, GPO Box U1987, Perth WA 6845, Australia
}

Abstract: Overuse of chemical fertilizer in apple production has resulted in environmental contamination in China. Existing research related to fertilizer use efficiency has focused on grain crops, and few studies have considered cash crops despite the significant structural shift of fertilizer application from grain to cash crops and the impacts of climate factors on fertilizer use efficiency. This paper employed a stochastic frontier method to examine the technical efficiency and fertilizer use efficiency of apple production by adopting panel data of eight major apple production provinces in China from 1992 to 2014. Further, the panel random-effects Tobit model was used to explore the factors influencing fertilizer use efficiency. The fertilizer use efficiency score ranged within $0.002-0.878$, with a mean value of 0.472 , which was much lower and had greater variability than technical efficiency with an average value of 0.868 . Irrigation fees, land size, non-agricultural employment opportunities, apple planting area ratio and fertilizer prices had significant positive effects on fertilizer use efficiency in apple production. Disaster ratio, precipitation, sunshine hours, and apple prices had a significant negative effect on fertilizer use efficiency. Formula fertilizer promoted by governments had no significant effect on improving fertilizer use efficiency. Fertilizer use efficiencies are more sensitive to education level and fertilizer price than non-agricultural employment opportunity and land size, and it is weakly sensitive to climate factors, apple price, and apple planting area ratio. Policies aimed at improving fertilizer use efficiency and reducing environment pollution should, therefore, focus on promoting non-agricultural employment opportunities and land circulation, strengthening and expanding rural extension services, raising environmental protection awareness and controlling fertilizer price, and encouraging farmers to adopt new production technology.

Keywords: Fertilizer use efficiency; Technical efficiency; Stochastic frontier function; Influencing factors; Apple

\section{Introduction}

As the world's largest apple production and consumption country, China's apple planting area and yield had increased to 2.22 million hectares and 41.39 million tons in 2017 , accounting for 45.03 and $49.81 \%$ of the world acreage and production, respectively (FAO, 2017). Additionally, with the rapid development of China's economy and the growth of per capita income, consumption structure has substantially changed. The demand for fruit as healthy food is increasing. As the largest proportion of fruit, the apple's sustainable production and development directly affect the improvement of the quality of life. In response to the rapid growth in the demand for apples, chemical fertilizer use per hectare increased from $300 \mathrm{~kg}$ in 1992 to $965.25 \mathrm{~kg}$ in 2014 for apple production, which contributed $52.43 \%$ to the increase in apple yields during this period, and chemical fertilizer use has exceeded twice the safe value (Bai et al., 2015). Although the marginal productivity of fertilizer use will decline because of excessive use, the use of chemical fertilizer in apple production will continue to increase because of relatively higher economic benefits compared with costs (Zhu and Chen, 2002), leading to low fertilizer use efficiency and negative environmental consequences. Specifically, low use efficiency and a high proportion of the loss of unabsorbed chemical fertilizer can lead to financial losses and serious local, regional, and global environmental pollution, such as water eutrophication (Domagalski et al., 2007), nitrate pollution of groundwater (Zhang et al., 1996), biodiversity loss (Asai et al., 2010), soil contamination and acidification (Guo et al., 2010; Aguilera et al., 2013), greenhouse gas emissions, and climate change (Kahrl et al., 2010; Wang et al., 2018), which can threaten the sustainable development of the apple industry. To control the use of chemical fertilizer, the Ministry of Agriculture of China put forward the "Zero Increase Action Plan for National Chemical Fertilizer Use by 2020" 
in 2015 - an effective means to successfully implement this plan is to increase chemical fertilizer use efficiency. Therefore, examining the chemical fertilizer use efficiency of apple production in China and the influencing factors for improving fertilizer use efficiency are worthy of further academic exploration.

Fertilizer use efficiency is a key indicator to assess the effective utilization rate of fertilizer and could be used to address environmental pollution from a fertilizer input (Lassaletta et al., 2014). A number of studies have analyzed fertilizer use efficiency from an agronomic and economic perspective. There are four types of fertilizer use efficiencies commonly used in agronomy: agronomic use, physiological use, internal use, and recovery efficiencies (Ladha et al., 2005; Zhang et al., 2012; Lassaletta et al., 2014). Mahajan et al. (2012) studied the agronomic use efficiencies of four amounts of nitrogen fertilizer application under two irrigation regimes of dryseeded rice in India; nitrogen fertilizer agronomic use efficiency was highest at $36.9 \mathrm{~kg} \mathrm{~kg}^{-1}$ when nitrogen fertilizer use was $60 \mathrm{~kg} \mathrm{ha}^{-1}$ under a 20-kPa irrigation regime. Ladha and Chakraborty (2016) evaluated synthetic nitrogen fertilizer recovery efficiency, and showed that the recovery efficiency was only $47 \%$ and much of $53 \%$ of the nitrogen in the surplus fertilizer would be lost to the environment (Krupnik et al., 2004). Quemada and Gabriel (2016) measured nitrogen fertilizer use efficiency by nitrogen physiological use efficiency and nitrogen recovery efficiency, and then identified the interactions between water- and nitrogen-use efficiency and discussed approaches for simultaneously increasing nitrogen and water use efficiency. Sarkar et al. (2018) indicated that polymer-coated novel controlled-release rock phosphate formulations could significantly improve phosphorus use efficiency. Chen et al. (2017) found that nitrogen agronomic efficiency, recovery efficiency, physiological efficiency, and partial factor productivity of coated compound fertilizer were higher than ordinary uncoated compound fertilizer, with efficiency values of 23.68-30.88, 42.13-61.51, 51.61-61.12, and 64.53-72.43\%, respectively. Meanwhile, a $20 \%$ decrease in nitrogen application rate was possible with coated compound fertilizer without yield reduction and with savings in labor and time. Additionally, site-specific and real-time nitrogen management, slow release and controlled-release fertilizers, and use of urease inhibitor and nitrification inhibitor can also improve fertilizer use efficiency (Shaviv, 2001; Quemada and Gabriel, 2016; Marcela et al., 2018).

Fertilizer use efficiency from an agronomic perspective is usually measured in experiments under strict conditions that do not always reflect real farmers' management (Gutierrez et al., 2017); consequently, many scholars turn to research fertilizer use efficiency from the perspective of economics. The input use efficiency is defined and measured by the ratio of minimum feasible to observed use of an input when keeping the observed levels of output and other inputs constant (Reinhard et al., 1999; Abay et al., 2004), and it mainly focuses on water use efficiency (Malano et al., 2004; Rodriguez et al., 2004; Speelman et al., 2008) and pesticide use efficiency (Oude Lansink and Silva, 2004; Singbo et al., 2015). However, few studies have focused on fertilizer use efficiency, and the researchers have mainly focused on China, a nation that accounts for one-third of the world's fertilizer use. Wu (2011) estimated the chemical fertilizer use efficiency of China in 2007 and found that excessive use of chemical fertilizers was as much as two-thirds of the actual amount. Ma et al. (2014) calculated the chemical fertilizer use efficiency of Taihu Basin in China and found that fertilizer use efficiency of rice production in 2008 was 0.254 and could be significantly improved. Liu et al. (2017) indicated that the mean fertilizer use efficiency of grain crops was 0.603 in China from 1997-2012 and found higher fertilizer use efficiency in the eastern China compared with the central and western regions of China. Thus, fertilizer use efficiency is relatively low in China and could be substantially improved by increasing fertilizer management practices and environmental awareness, the degree of education, off-farm income, and a positive risk attitude (Wu, 2011; Ma et al., 2014; Shi et al., 2015; 
Quemada and Gabriel, 2016; Liu et al., 2017).

Studies have commonly measured fertilizer use efficiency in agronomic terms by using field experiment methods because they are accurate, easy to explain, and have a sound theoretical foundation (Mahajan et al., 2012). However, such experimental methods have usually imposed many strict conditions and neglected the human adaptive activities regarding climate and social factors; consequently, the results are not suitable for a wide range of fertilizer use efficiency evaluations and may lead to policy implication bias (Gutierrez et al., 2017). Economic methods of evaluating fertilizer use efficiency can overcome the shortcomings of agronomic methods by considering human adaptation to social, natural, and climate factors. Taking the change in input as an adaptation to social, natural, and climate factors, the input use efficiency can commonly be measured by data envelopment analysis (DEA) and stochastic frontier analysis (SFA) models based on the frontier production theory, which are non-parametric and parametric methods, respectively. Speelman et al. (2008) measured the water use efficiency of agriculture production in South Africa with a DEA model and showed that it was only 0.43 and had substantial potential for improvement. Singbo et al. (2015) analyzed pesticide use efficiency of vegetable production in Benin with a DEA model and found that efficiency was 0.635 and pesticides were overused. Focused on the research of fertilizer use efficiency, Angulo-Meza et al. (2018) assessed the eco-efficiency of organic blueberry production with a multi-objective DEA model, and showed that fertilizers made the largest contribution to eco-inefficiency. Zhang and Bai (2017) evaluated the fertilizer use efficiency of apple production using a DEA model in the Loess Plateau of China and found regional characteristics of fertilizer use efficiency. Because DEA cannot distinguish the effects of statistical noise from those of productive inefficiency, such as measurement error, missing variables, and weather, which are likely to play an important role in agriculture, SFA was recommended for use in agricultural production (Coelli, 1995). Wu (2011) and Ma et al. (2014) used SFA with a translog model to estimate fertilizer use efficiency of rice and wheat in China, and found that it was lower than the world average and had regional differences. Wang et al. (2017) explored the spatial and temporal characteristics of fertilizer use efficiency in China. The results indicated that the eastern region of China had the lowest efficiency and the northeast region of China had the highest efficiency. Furthermore, the main factors impacting fertilizer use efficiency were discussed, and the results indicated that household characteristics, farm characteristics, marketization characteristics, public service, and type of fertilizer significantly affected fertilizer use efficiency (Ma et al., 2014; Quemada and Gabriel, 2016; Wang et al., 2017; Zhang and Bai, 2017).

Although studies have contributed to evaluating the fertilizer use efficiency of crops, a gap remains in the research. First, studies related to fertilizer use efficiency have focused on grain crops, and few have addressed cash crops and the significant structural shift of fertilizer application from grain to cash crops. Cash crops account for more than $50 \%$ of China's fertilizer use; thus, an analysis of the fertilizer use efficiency of cash crops and the determinants for improving efficiency is necessary. Second, researchers have not considered climate change into the study of fertilizer use efficiency. Because climate change can affect agricultural production activities and adaptation behaviors, it has a substantial impact on the application of fertilizer and its efficiency. Rising temperatures and changes in precipitation will lead to the volatilization or loss of soil minerals, which will require more fertilizer input. In addition, temperature changes will affect the biophysical and chemical processes of soil, affecting the fertilizer use efficiency. Therefore, to fill in these gaps, this paper attempts to use apples as a cash crop to analyze the fertilizer use efficiency and the determinants for improving efficiency in eight major apple production provinces in China. Because apples are a traditional advantage high-value and long growth-cycle cash 
crop of China, this crop is essentially different from grain crops. Moreover, formula fertilizer technology has been promoted by the Ministry of Agriculture of China since 2005, and the effects of this technology on fertilizer use efficiency will be verified. In this paper, climate change, fertilizer price, and formula fertilizer were considered important impact factors and selected disaster ratio, precipitation, temperature, and sunshine hours represent the natural environment and climate change.

The remainder of the paper is organized as follows. Research methodology is presented in Section 2, followed by data sources and description in Section 3. Section 4 provides the estimated results of technical efficiency, fertilizer use efficiency, and its influencing factors; Section 5 discusses the major findings, and Section 6 concludes with policy implications.

\section{Methodology}

Stochastic frontier production function model is widely used to evaluate efficiency and productivity, which was firstly proposed by Battese and Coelli (1995). The model can consider the stochastic factors, it is mainly applied in the field of agriculture and economy. The stochastic frontier production function is generally expressed as:

$$
y_{i t}=f\left(x_{i t}, t, \beta\right) \exp \left(v_{i t}-u_{i t}\right)
$$

where $y_{i t}$ is the output of $i$-th observation in $t$ year; $x_{i t}$ is a vector of inputs including labor, fertilizer and capital; $t$ is time variable; $\beta$ is a vector of parameters to be estimated; $v_{i t}$ is a random error and $v_{i t} \sim i i d\left(0, \sigma^{2}{ }_{v}\right) ; u_{i t}$ denotes technical inefficiency in production process, which is presumed to be nonnegative and distributed independently of $v_{i t}, u_{i t} \sim i i d\left(m_{i t}, \sigma_{u}^{2}\right)$, and

$$
m_{i t}=\delta_{0}+\sum_{q} \delta_{q} z_{i t}+w_{i t}
$$

where $m_{i t}$ is the technical inefficiency of $i$-th observation in $t$ year, $z_{i t}$ is a vector of variables which may influence the efficiency; $\delta$ is a vector of parameters to be estimated; $w_{i t}$ is a random error.

Technical efficiency can be expressed as:

$$
T E_{i t}=y_{i t} /\left(f\left(x_{i t}, t, \beta\right) \exp \left(v_{i t}\right)\right)=\exp \left(-u_{i t}\right)
$$

In this paper, we use the translog production function form, because it is a second-order expansion of any logarithmic functional form, and has fewer restrictions than some other popular functional forms. The stochastic frontier translog production function is specified as:

$$
\begin{aligned}
& \ln y_{i t}=\beta_{0}+\beta_{1} \operatorname{lnla}_{i t}+\beta_{2} \ln f e r_{i t}+\beta_{3} \ln w z_{i t}+\beta_{4} t+\beta_{5}(\operatorname{lnla} i t)^{2}+\beta_{6}\left(\ln f e r_{i t}\right)^{2}+\beta_{7}\left(\ln w z_{i t}\right)^{2} \\
& +\beta_{8} t^{2}+\beta_{9} \operatorname{lnla}_{i t} \operatorname{lnfer} \text { fit }+\beta_{10} \operatorname{lnla}_{i t} \ln w z_{i t}+\beta_{11} \operatorname{lnfer_{it}} \ln w z_{i t}+\beta_{12} \text { tlnla }_{i t} \\
& +\beta_{13} t \ln \mathrm{fer}_{i t}+\beta_{14} t \ln w z_{i t}+v_{i t}-u_{i t}
\end{aligned}
$$

where $y_{i t}$ is the apple yield per mu (1/15 ha); $i=1,2, \ldots, 8$ refers to apple production provinces in China; $t=1$, $2, \ldots, 23$ denotes the year from 1992 to 2014, which captures technical progress as a time trend; $l a_{i t}$ is the labor input per mu (1/15 ha); fer $_{i t}$ is the chemical fertilizer input per mu (1/15 ha), which is measured in terms of active ingredients by adding the pure quantity of nitrogen, phosphorus pentoxide, and potassium oxide; $w z_{i t}$ is material input except the chemical fertilizer per mu (1/15 ha).

Fertilizer use efficiency $(F U E)$ is defined as the ratio of minimum quantity of chemical fertilizer required to the observed quantity. According to Reinhard et al. (1999), fertilizer use efficiency can be expressed as follows:

$$
F U E=\{\min [\theta ; f(x, \theta f e r ; \beta) \geq y]\} \leq 1
$$

where $f(x, \theta f e r ; \beta)$ is the frontier production function; $\theta$ is the ratio of minimum fertilizer input to observed 
fertilizer input; $x$ denotes the vector of other inputs except fertilizer; $\beta$ is the parameter vector to be estimated. It can be understood that fertilizer use will be efficient if the overall production process is technically efficient. This means that the minimum feasible fertilizer is applied if there are no technical efficiency losses (Ma et al., 2014), let $u_{i t}=0$ and replace $f e r_{i t}$ with $\theta f e r_{i t}$ in Eq.(4), it can then be expressed as:

$$
\begin{aligned}
& \ln y_{i t}=\beta_{0}+\beta_{1} \operatorname{lnla}_{i t}+\beta_{2} \ln \theta f e r_{i t}+\beta_{3} \ln w z_{i t}+\beta_{4} t+\beta_{5}\left(\ln l a_{i t}\right)^{2}+\beta_{6}\left(\ln \theta f e r_{i t}\right)^{2} \\
& +\beta_{7}\left(\ln w z_{i t}\right)^{2}+\beta_{8} t^{2}+\beta_{9} \operatorname{lnla} a_{i t} \ln \theta f e r_{i t}+\beta_{10} \operatorname{lnla} \ln _{i t} \ln w z_{i t}+\beta_{11} \ln \theta f e r_{i t} \ln w z_{i t} \\
& +\beta_{12} t \ln l a_{i t}+\beta_{13} t \ln \theta f e r_{i t}+\beta_{14} t \ln w z_{i t}+v_{i t}
\end{aligned}
$$

Subtracting Eq. (4) from (6), we obtain

$\left(\beta_{2}+\beta_{9} \operatorname{lnla}_{i t}+\beta_{11} \ln w z_{i t}+\beta_{13} t\right)\left(\ln \theta f e r_{i t}-\ln f e r_{i t}\right)+\beta_{6}\left[\left(\ln \theta f e r_{i t}\right)^{2}-\left[\left(\ln f e r_{i t}\right)^{2}\right]+u_{i t}=0\right.$

From the definition of fertilizer use efficiency, we have

$$
\ln F U E_{i t}=\ln \theta=\ln \left(\theta f e r_{i t} / f e r_{i t}\right)=\ln \theta f e r_{i t}-\ln f e r_{i t}
$$

$F U E_{i t}$ is then solved from Eq. (7) as:

$$
F U E_{i t}=\exp \left\{\left(-\lambda_{i t} \pm \sqrt{\lambda_{i t}{ }^{2}-4 \beta_{6} u_{i t}}\right) / 2 \beta_{6}\right\}
$$

where

$$
\lambda_{i t}=\partial \ln y_{i t} / \partial \ln f e r_{i t}=\beta_{2}+\beta_{9} \operatorname{lnla} a_{i t}+\beta_{11} \ln w z_{i t}+\beta_{13} t+2 \beta_{6} \ln f e r_{i t}
$$

$\lambda_{i t}$ is known as the fertilizer output elasticity in the translog production function.

After estimating the fertilizer use efficiency, the factors influencing fertilizer use efficiency can be analyzed with the panel random-effects Tobit regression model:

$$
F U E_{i t}=\kappa_{0}+\sum_{m} \kappa_{m} \gamma_{i t}+\mu_{i t}
$$

where $F U E_{i t}$ is fertilizer use efficiency of $i$-th province in $t$ year, $\gamma_{i t}$ is a vector of variables that may influence the efficiency of the province (the influencing factors are detail in section 3); $\kappa$ is a vector of parameters to be estimated; $\mu_{i t}$ is a random error.

\section{Data sources and description}

\subsection{Data sources and description of variables in production function}

This study analyzes the fertilizer use efficiency of apple production by using the data set of eight major apple production provinces in China, whose apple planting area and yields have accounted for $89.07 \%$ and $98.99 \%$ of China's totals, respectively. Apples represent the largest high-value cash crop in China, and their production consumes large amounts of chemical fertilizer. The fertilizer use in apple production had accounted for $14.53 \%$ of the total use in agriculture production in 2014. Thus, the level of fertilizer use efficiency in apple production has a great influence on the agricultural non-point source pollution caused by fertilizer.

The data used in the production function are from the China Agricultural Product Cost-Benefit Compilation (1993-2015) (National Development and Reform Commission of China, 1993-2015). The data have been used in several other studies (e.g., Shi et al., 2015; Zhou et al., 2015). A three-stage random sampling procedure is used to choose the sample counties, villages, and finally households in each province, and then the apple production cost and revenue data are collected from the selected households. The provincial level data are estimated by the selected individual household data, which are not published (Zhou, et al., 2015). The data are, for example, apple yields, apple revenue, labor input (days), chemical fertilizer input, irrigation fees, and material capital inputs. Each variable in the dataset is measured by the same land unit, which is one mu (1/15ha). Thus, in this paper, the input 
and output variables are all counted per mu, and the land size is not considered. Three variables are included as input variables in the translog frontier production function, for example, in Eq.(3), and labor input is the sum of days of family labor and hired labor; chemical fertilizer use, which is the pure quantity of nitrogen, phosphorus pentoxide, and potassium oxide; and material input. Material input comprises, for example, irrigation cost and machine cost, which is material cost except for the cost of chemical fertilizer, and it is smoothed by the producer price index of agricultural products in different regions in China to eliminate the inflation. The panel data we use has 184 observations from eight major apple production provinces: Shandong, Liaoning, Hebei in Bohai Bay and Shanxi, Henan, Gansu, Shaanxi, and Ningxia in the Loess Plateau region of China for each year from 1992-2014. The units and descriptive statistics of input and output variables used in the production function are presented in Table 1.

Table 1

212 Descriptive statistics of variables used in the production function and fertilizer use efficiency model

\begin{tabular}{|c|c|c|c|c|c|c|c|}
\hline & Variables & Unit & Mean & Median & Std Dev. & Min. & Max. \\
\hline \multirow{4}{*}{$\begin{array}{l}\text { Variables in } \\
\text { production } \\
\text { function }\end{array}$} & apple yield & kg/mu(1/15ha) & 1735.490 & 1740.880 & 479.241 & 642.840 & 3211.180 \\
\hline & labor & day/mu(1/15ha) & 49.852 & 44.470 & 20.227 & 17.530 & 118.100 \\
\hline & fertilizer & kg/mu(1/15ha) & 51.937 & 46.111 & 23.134 & 5.375 & 134.360 \\
\hline & material & $\mathrm{CNY} / \mathrm{mu}(1 / 15 \mathrm{ha})$ & 353.472 & 322.234 & 161.938 & 126.512 & 834.782 \\
\hline \multirow{19}{*}{$\begin{array}{l}\text { Variables } \\
\text { influencing } \\
\text { fertilizer use } \\
\text { efficiency }\end{array}$} & \multicolumn{7}{|l|}{ Household characteristics } \\
\hline & Education & year & 7.869 & 8.145 & 1.004 & 4.271 & 10.811 \\
\hline & Income & $\mathrm{CNY}$ & 2762.950 & 2355.140 & 1548.850 & 902.181 & 8181.890 \\
\hline & Irrigation fee & $\mathrm{CNY} / \mathrm{mu}(1 / 15 \mathrm{ha})$ & 35.048 & 26.844 & 32.451 & 1.0169 & 233.780 \\
\hline & Land size & $\mathrm{mu}(1 / 15 \mathrm{ha})$ & 1.675 & 1.650 & 0.333 & 1.050 & 2.500 \\
\hline & \multicolumn{7}{|l|}{ Natural environment and climate change } \\
\hline & Disaster ratio & $\%$ & 0.388 & 0.361 & 0.263 & 0.087 & 0.770 \\
\hline & Precipitation & $\mathrm{mm}$ & 41.454 & 41.575 & 12.740 & 10.621 & 76.940 \\
\hline & Temperature & ${ }^{\circ} \mathrm{C}$ & 11.806 & 11.873 & 1.486 & 8.150 & 14.652 \\
\hline & Sunshine hours & hours & 200.674 & 199.162 & 21.432 & 146.556 & 253.713 \\
\hline & Apple planting area ratio & $\%$ & 0.055 & 0.039 & 0.068 & 0.005 & 0.805 \\
\hline & Financial ratio of agriculture & $\%$ & 0.134 & 0.108 & 0.117 & 0.013 & 0.834 \\
\hline & Effective irrigation area ratio & $\%$ & 0.441 & 0.365 & 0.192 & 0.121 & 1.618 \\
\hline & Fertilizer price & $\mathrm{CNY} / \mathrm{kg}$ & 3.477 & 3.354 & 0.638 & 1.659 & 6.259 \\
\hline & Apple price & $\mathrm{CNY} / \mathrm{kg}$ & 1.862 & 1.395 & 1.168 & 0.474 & 6.233 \\
\hline & Non-agricultural employment opportunity & $\%$ & 0.348 & 0.340 & 0.096 & 0.119 & 0.545 \\
\hline & \multicolumn{7}{|l|}{ Dummies } \\
\hline & Formula fertilizer & $\begin{array}{l}1=\text { after } 2005, \\
0=\text { other year }\end{array}$ & 0.435 & 0 & 0.497 & 0 & 1 \\
\hline & Region & $\begin{array}{l}1=\text { Loess Plateau, } \\
0=\text { Bohai Bay }\end{array}$ & 0.625 & 1 & 0.485 & 0 & 1 \\
\hline
\end{tabular}

In Table 1, the average apple yield in each province from 1992-2014 is $1735.490 \mathrm{~kg}$ per mu, with a range from $642.840 \mathrm{~kg}$ to $3211.18 \mathrm{~kg}$ per mu. The labor input in each province varies widely from a minimum value of 17.530 to a maximum of 118.100 days per mu, with an average of 49.852 days per mu. Average chemical fertilizer input in each province is $51.937 \mathrm{~kg}$ per mu, with minimum 5.375 and maximum $134.360 \mathrm{~kg}$ per mu. Average material input in each province is equal to $353.472 \mathrm{CNY}$ per mu, on a scale from 126.512 to $834.782 \mathrm{CNY}$ per mu. Further, the average value of the variables in the Loess Plateau region are calculated to compare with the 
results of Bai (2017), who surveyed apple production farmers in 2015 in the Loess Plateau region. The average apple yield, labor input, chemical fertilizer, and material inputs in this paper are $1909.890 \mathrm{~kg}, 30.48$ days, 72.563 $\mathrm{kg}$ and $148.283 \mathrm{CNY}$ per mu in the Loess Plateau, respectively, which are closer to the results of $1868.688 \mathrm{~kg}$, 27.5 days, $76.513 \mathrm{~kg}$ (converted into the pure quantity of nitrogen, phosphorus pentoxide and potassium oxide with the coefficient of 20\%), and 182 CNY per mu in the Loess Plateau in Bai (2017), respectively. In addition, reliability tests on the data show the Cronbach's $\alpha$ is 0.694 , indicating the data has better internal consistency and stability. Thus, the data used in this paper are reliable and can be used to calculate fertilizer use efficiency.

\subsection{Data sources and description of influencing factors}

Agriculture production is a combined result of nature and society and is affected by the natural environment and by economic and social factors. Thus, the factors we identify that possibly influence fertilizer use efficiency include the household characteristics, the natural environment and climate change, and economic and social factors. The descriptive statistics of influencing factors are listed in Table 1. The influencing factors of income and natural disaster ratio are from the China Statistical Yearbook (1993-2015) (National Bureau of Statistics of China, 1993-2015a). Education level, apple planting area ratio, financial ratio of agriculture, effective irrigation area ratio and non-agricultural employment opportunity are obtained from the China Rural Statistical Yearbook (1993-2015) (National Bureau of Statistics of China,1993-2015b). Irrigation fee, land size, fertilizer price and apple price are collected from China Agricultural Product Cost-Benefit Compilation (1993-2015) (National Development and Reform Commission of China, 1993-2015). Climate change is represented by average monthly temperature, average monthly precipitation, and monthly sunshine hours, and the data come from the China surface climate data monthly data set", and are calculated by the average values of the 121 meteorological stations in the study area. These data have been used in several other studies (e.g., Bai et al., 2015; Wang et al., 2018). In addition, income and apple price are deflated by the rural consumer price index in different regions of China to eliminate inflation. Irrigation fee and fertilizer price are deflated by the producer price index of agricultural products in different regions of China to eliminate inflation. Further, reliability tests on the influencing factors show that the Cronbach's $\alpha$ is 0.619 , indicating the factors has better internal consistency and stability.

Household characteristics include education level, income, irrigation fee, and land size. Education level is measured by the weighted average of the rural laborers' average years of attending school. With a higher education level, more scientific methods for planting and fertilizing tend to be mastered easier, which is a benefit for fertilizer use efficiency (Wu, 2011; Ma et al., 2014). Higher education also means a higher awareness of the role of fertilizer, which may lead to greater reliance on fertilizer as an input (Lamb, 2003). Thus, the effect of education on fertilizer use efficiency is ambiguous. The average education level is 7.869 years; thus, the rural laborers have on average junior middle school education experiences, and this result is consistent with Bai (2017), who showed the average education level is 7.55 years with survey data from the Loess Plateau. The income variable is annual per capita rural income of each province, which also has an ambiguous effect on fertilizer use efficiency. With the increase in income, on the one hand, the production inputs tend to be increased and excessive fertilizer use may cause low fertilizer use efficiency; on the other hand, high-quality fertilizer may be used, promoting the fertilizer absorption and improving the fertilizer use efficiency. The average annual per capita rural income is $2762.954 \mathrm{CNY}$, with

\footnotetext{
* China surface climate data monthly data set come from National Meteorological Information Center (https://data.cma.cn/data)
} 
wide variation. Irrigation fee is represented by an average irrigation fee per mu in each province. According to Ju et al. (2009) and Kahrl et al. (2010), irrigation can promote fertilizer to interact with water and improve fertilizer use efficiency; thus, the effect of irrigation fee is expected to be positive. The average irrigation fee is 35.048 CNY per mu, with a range from 1.017 to $233.78 \mathrm{CNY}$ per mu, which shows a huge variation in irrigation in different provinces. Land size is measured by per capita apple farm size and is expected to improve fertilizer use efficiency. Farmers with larger land size will tend to adopt advanced agricultural production techniques and agricultural management methods to reduce the fixed input and management cost of unit area, which has a positive impact on fertilizer use efficiency (Wang et al., 2017). The average land size is $1.675 \mathrm{mu}$ with a minimum and maximum value of 1.05 and $2.5 \mathrm{mu}$, respectively, and the average land size is slightly lower than the results of Bai (2017), who shows the average size is $1.911 \mathrm{mu}$ in the Loess Plateau.

Natural environment and climate change are represented by the natural disaster ratio caused by floods and droughts, the average monthly precipitation, the average monthly temperature and sunshine hours. More natural disasters make farmers reduce the material inputs for adapting to the decrease in yield, which may have a positive effect on fertilizer use efficiency, but an extreme climatic condition may accelerate fertilizer penetration and evaporation (Salvo et al., 2013). Thus, the effect of climatic factors on fertilizer use efficiency is ambiguous. The natural disaster ratio is calculated as disaster area divided by the cultivated area of the province, and its average value is 0.388 , which means almost $38.8 \%$ of apple planting area will suffer a natural disaster on average in any year. The climate condition has an obviously regional characteristic, and the change of precipitation is the biggest, followed by temperature and sunshine hours.

Economic and social characteristics include the ratio of apple planting area to cultivated area in each province, the ratio of financial fund for agriculture to all financial fund, the ratio of effective irrigation area to cultivated area in each province, fertilizer price, apple price, and non-agriculture employment opportunity. The impacts of the apple planting area ratio and agriculture financial fund ratio on fertilizer use efficiency are considered to be positive, because with their increases, the government pays more attention to investment in the apple industry. This can improve the apple production technology, management level, and production environment. The average apple planting area ratio and agriculture financial fund ratio are 0.055 and 0.134 , respectively. A higher effective irrigation area ratio indicates a better condition for apple production, which can increase the apple output and improve the fertilizer use efficiency by promoting the interaction of water and fertilizer. However, excessive irrigation may accelerate the penetration rate of fertilizer, which may result in lower fertilizer use efficiency. Thus, the effect of effective irrigation area ratio is ambiguous, and its average value is 0.441 over the sample. A higher fertilizer price indicates less fertilizer used for apple production, which may increase the fertilizer use efficiency; however, it may also lead to the use of low-quality fertilizer and reduce the fertilizer use efficiency. Thus, the effect of fertilizer price on fertilizer use efficiency is ambiguous. The average fertilizer price is 3.477 CNY per kilogram, which is almost the same as the survey value of 3.346 CNY per kilogram in Bai (2017). The high price of apples may have a negative effect on fertilizer use efficiency. A higher apple price may stimulate more fertilizer use, leading to low fertilizer use efficiency. The average price of apples is $1.862 \mathrm{CNY}$ per kilogram during the research period, a little lower than the survey value of 1.919 CNY per kilogram in Bai (2017).

The effect of non-agriculture employment opportunity on fertilizer use efficiency is considered to be ambiguous. High non-agriculture employment opportunity means more rural laborers obtain jobs outside and put less labor input to agriculture, resulting in more fertilizers used (Lamb, 2003). Additionally, high non-agriculture 
employment opportunity means high income. On the one hand, the high income may cause more fertilizer to be purchased and used and, at last, lower fertilizer use efficiency; on the other hand, high income may prompt the purchase of high-quality fertilizer, which is conducive to the improvement of fertilizer use efficiency. In addition, with the increase in non-agriculture income, agricultural income is no longer the main source of income, and there is no need to use more fertilizer to increase agricultural production, which improves the fertilizer use efficiency (Shi et al., 2011; Ma et al., 2014). Non-agriculture employment opportunity is the ratio of the residual value of rural laborers and agricultural laborers to the rural laborers. The average value of the ratio is 0.348 , which means $34.8 \%$ of the rural laborers have a non-agriculture job, and it is lower than the ratio of 0.455 in Bai (2017), who surveyed the apple householders in 2015 in the Loess Plateau. This difference may be caused by the increasing trend of non-agriculture employment in recent years.

The policy dummy variable is expected to capture the policy effect of formula fertilizer from 2005 , which supposes the value is 0 before 2005, and 1 afterward. The coefficient of the region dummy variable indicates the regional difference of the fertilizer use efficiency, which captures the impacts of neglected variables in the model.

\section{Empirical results}

\subsection{Model test and choice}

The production frontier functional forms are tested by using the likelihood-ratio (LR) statistic. The results are presented in Table 2. The first hypothesis test shows that the translog production function is preferred to the CobbDouglas (C-D) form at a 5\% significance level. The second and third hypothesis tests show that technical progress exists and is not neutral. The last hypothesis test shows the technical inefficiency model is necessary. Thus, the translog form that includes the time and other variables that interacted with time and technical inefficiency influence factors is the preferred specification for estimation.

Table 2

Model specification tests

\begin{tabular}{|c|c|c|c|c|}
\hline Null hypothesis & LR value & Degree of freedom $(\mathrm{k})$ & Threshold $\mathrm{X}_{0.05}{ }^{2}(\mathrm{k})$ & Decision \\
\hline C-D production function $\mathrm{H}_{0}: \beta_{5}=\beta_{6=\ldots}=\beta_{14}=0$ & 45.318 & 10 & 18.307 & Reject \\
\hline No technical progress $\mathrm{H}_{0}: \beta_{4}=\beta_{8=} \beta_{12=} \beta_{13}=\beta_{14}=0$ & 32.578 & 5 & 11.070 & Reject \\
\hline Non-neutral technical progress $\mathrm{H}_{0}: \beta_{12}=\beta_{13}=\beta_{14}=0$ & 22.898 & 3 & 7.815 & Reject \\
\hline No technical efficiency influencing factors $\mathrm{H}_{0}: \delta_{1}=\delta_{2=\ldots}=\delta_{11}=0$ & 40.578 & 12 & 21.026 & Reject \\
\hline
\end{tabular}

\subsection{Estimation results of SFA model}

The maximum likelihood function is used to estimate Eq.(1) and Eq.(2) with the one-stage method by using FRONTIER 4.1, introduced by Battese and Coelli (1995). The results are reported in Table 3 (For comparison, the influencing factors of TE is presented in Table 5). The estimated value of $\gamma$ is 0.742 , and this result is significant at the level of $10 \%$, indicating that $74.2 \%$ of the error is because of technical inefficiency and only $25.8 \%$ is from other random factors that cannot be controlled; thus, the stochastic frontier approach is reasonable.

In Table 3, the coefficients of material input and its interaction with time are negative and significant, indicating the excessive input of material; the results are similar to Bai et al. (2015). The coefficient of labor is positive but not significant, and the quadratic coefficient is negative and significant, indicating that the contribution of labor to apple yields is positive, but with diminishing marginal impact, more labor input can make more apple output and the effect of labor to apple yields is an inverted U-shape. The coefficient of time is positive and significant, which denotes technical progress. Further, the interaction of time with material is significantly negative, indicating that the technical progress is not neutral. The coefficients of the interaction of material and 
labor, and material and fertilizer, are all positive and significant at a 5\% significance level, indicating the complementary relationships exist between them. Although the interacted item coefficient of fertilizer and labor is not significant, the symbol of the coefficient indirectly implies the substitute relationship between fertilizer and labor. In other words, reducing fertilizer can be compensated by increasing labor input.

Table 3

$337 \quad$ Parameter estimated results

\begin{tabular}{llllll}
\hline Variables & Coefficient & S.E & Variables & Coefficient & S.E \\
\hline Intercept $\left(\beta_{0}\right)$ & $10.101^{* * *}$ & 1.111 & Labor*fertilizer $\left(\beta_{9}\right)$ & -0.219 & 0.189 \\
Labor $\left(\beta_{1}\right)$ & 0.172 & 0.755 & Labor*material $\left(\beta_{10}\right)$ & $0.370^{* * *}$ & 0.152 \\
Fertilizer $\left(\beta_{2}\right)$ & -0.593 & 0.820 & Fertilizer*material $\left(\beta_{11}\right)$ & $0.329^{* *}$ & 0.164 \\
Material $\left(\beta_{3}\right)$ & $-1.369^{* *}$ & 0.641 & Time*labor $\left(\beta_{12}\right)$ & 0.010 & 0.012 \\
Time $\left(\beta_{4}\right)$ & $0.200^{* * *}$ & 0.049 & Time*fertilizer $\left(\beta_{13}\right)$ & 0.0002 & 0.013 \\
Quadratic labor $\left(\beta_{5}\right)$ & $-0.183^{*}$ & 0.120 & Time*material $\left(\beta_{14}\right)$ & $-0.037^{* * *}$ & 0.010 \\
Quadratic fertilizer $\left(\beta_{6}\right)$ & -0.043 & 0.088 & $\sigma^{2}$ & $0.055^{* * *}$ & 0.012 \\
Quadratic material $\left(\beta_{7}\right)$ & -0.065 & 0.100 & $\gamma$ & $0.742^{*}$ & 0.069 \\
Quadratic time $\left(\beta_{8}\right)$ & -0.0004 & 0.001 & $\log$ likelihood & 76.449 & \\
\hline
\end{tabular}

Notes: $*{ }^{* *}$ and $* * *$ represent the significance levels of $10 \%, 5 \%$ and $1 \%$, respectively

\subsection{Results of technical efficiency and fertilizer use efficiency}

Technical efficiency is calculated using Eq. (3), and the results are shown in Fig.1. Technical efficiency of apple production ranges from 0.745 to 0.938 with a mean value of 0.868 in our research period of 1992-2014. This result indicates that farmers achieve approximately $86.8 \%$ of potential output by using the given inputs, and could achieve a 13.2\% further output increase in apple production with the existing technology and remaining constant inputs if the technical inefficiency were completely eliminated. Technical efficiency fluctuates around a rising trend, but the technical efficiency change is not significant. Technical efficiency increases 0.745 in 1992 to 0.891 in 2014 , with an annual technical efficiency growth of $0.82 \%$. Improving technical efficiency may be an important means to increase the income of apple households. This result is consistent with Singbo et al. (2015) and Bai (2012). Singbo et al. (2015) found that the average technical efficiency of vegetable producers was 0.849 in Benin over the period of 2009-2010, and Bai (2012) indicated it was 0.855 in apple production from 19992009. These results are similar to our results.

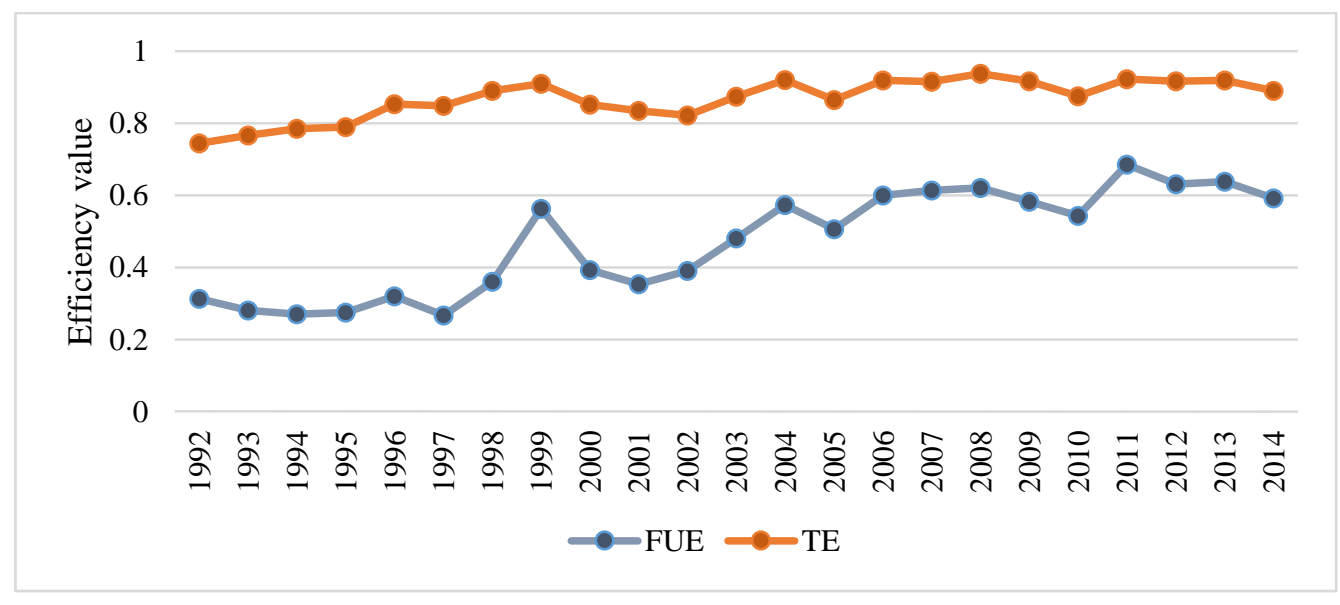

Fig. 1. Technical efficiency and fertilizer use efficiency during 1992-2014

Fertilizer use efficiency is derived using Eq. (9) and described in Fig.1, with detailed annual results listed in

Table 4. In Fig.1, fertilizer use efficiency is lower than technical efficiency. The result in Table 4 indicates that 

greater variability than technical efficiency. The low fertilizer use efficiency indicates that the fertilizer input can be reduced by $52.8 \%$ to maintain the apple output with current agricultural technologies and other observed inputs.

358 Additionally, the reduced fertilizer will not only have no negative impact on apple production, but also improve 359 the technical efficiency.

360 Table 4

361 Fertilizer use efficiencies in each province during 1992-2014

\begin{tabular}{|c|c|c|c|c|c|c|c|c|c|c|c|}
\hline Year & Hebei & Shanxi & Liaoning & Shandong & Henan & Shaanxi & Gansu & Ningxia & Bohai & Loess Plateau & mean \\
\hline 1992 & 0.391 & 0.488 & 0.544 & 0.460 & 0.009 & 0.140 & 0.057 & 0.413 & 0.465 & 0.221 & 0.313 \\
\hline 1993 & 0.510 & 0.076 & 0.227 & 0.579 & 0.050 & 0.171 & 0.056 & 0.578 & 0.439 & 0.186 & 0.281 \\
\hline 1994 & 0.049 & 0.451 & 0.118 & 0.557 & 0.004 & 0.084 & 0.125 & 0.769 & 0.241 & 0.287 & 0.270 \\
\hline 1995 & 0.401 & 0.391 & 0.261 & 0.509 & 0.153 & 0.091 & 0.320 & 0.073 & 0.391 & 0.206 & 0.275 \\
\hline 1996 & 0.340 & 0.496 & 0.251 & 0.512 & 0.297 & 0.118 & 0.337 & 0.204 & 0.368 & 0.291 & 0.319 \\
\hline 1997 & 0.056 & 0.053 & 0.365 & 0.284 & 0.507 & 0.204 & 0.418 & 0.246 & 0.235 & 0.286 & 0.267 \\
\hline 1998 & 0.107 & 0.316 & 0.686 & 0.457 & 0.525 & 0.071 & 0.484 & 0.239 & 0.417 & 0.327 & 0.361 \\
\hline 1999 & 0.266 & 0.449 & 0.761 & 0.615 & 0.388 & 0.812 & 0.841 & 0.372 & 0.547 & 0.572 & 0.563 \\
\hline 2000 & 0.165 & 0.506 & 0.447 & 0.673 & 0.186 & 0.296 & 0.205 & 0.660 & 0.428 & 0.371 & 0.392 \\
\hline 2001 & 0.059 & 0.479 & 0.360 & 0.577 & 0.108 & 0.801 & 0.321 & 0.122 & 0.332 & 0.366 & 0.353 \\
\hline 2002 & 0.251 & 0.371 & 0.636 & 0.780 & 0.108 & 0.766 & 0.028 & 0.184 & 0.556 & 0.291 & 0.391 \\
\hline 2003 & 0.658 & 0.393 & 0.727 & 0.835 & 0.103 & 0.634 & 0.218 & 0.276 & 0.740 & 0.325 & 0.481 \\
\hline 2004 & 0.752 & 0.863 & 0.680 & 0.817 & 0.275 & 0.776 & 0.264 & 0.160 & 0.750 & 0.468 & 0.573 \\
\hline 2005 & 0.495 & 0.624 & 0.778 & 0.703 & 0.064 & 0.527 & 0.223 & 0.636 & 0.659 & 0.415 & 0.506 \\
\hline 2006 & 0.681 & 0.851 & 0.603 & 0.861 & 0.612 & 0.775 & 0.030 & 0.386 & 0.715 & 0.531 & 0.600 \\
\hline 2007 & 0.769 & 0.734 & 0.850 & 0.738 & 0.373 & 0.738 & 0.009 & 0.695 & 0.786 & 0.510 & 0.613 \\
\hline 2008 & 0.748 & 0.800 & 0.837 & 0.870 & 0.541 & 0.701 & 0.005 & 0.467 & 0.818 & 0.503 & 0.621 \\
\hline 2009 & 0.534 & 0.767 & 0.814 & 0.834 & 0.573 & 0.749 & 0.002 & 0.387 & 0.727 & 0.496 & 0.583 \\
\hline 2010 & 0.413 & 0.726 & 0.590 & 0.804 & 0.458 & 0.528 & 0.308 & 0.517 & 0.602 & 0.507 & 0.543 \\
\hline 2011 & 0.764 & 0.862 & 0.575 & 0.738 & 0.778 & 0.687 & 0.332 & 0.747 & 0.692 & 0.681 & 0.685 \\
\hline 2012 & 0.557 & 0.777 & 0.408 & 0.878 & 0.834 & 0.820 & 0.326 & 0.451 & 0.614 & 0.642 & 0.631 \\
\hline 2013 & 0.680 & 0.709 & 0.501 & 0.831 & 0.682 & 0.712 & 0.384 & 0.601 & 0.671 & 0.618 & 0.638 \\
\hline 2014 & 0.612 & 0.613 & 0.313 & 0.818 & 0.803 & 0.601 & 0.211 & 0.758 & 0.581 & 0.597 & 0.591 \\
\hline mean & 0.446 & 0.556 & 0.536 & 0.684 & 0.366 & 0.513 & 0.239 & 0.432 & 0.555 & 0.421 & 0.472 \\
\hline
\end{tabular}

362

\subsection{Regression results of factors influencing fertilizer use efficiency}

The influencing factors model of fertilizer use efficiency is estimated by using a panel random-effects Tobit regression, and the result is shown in Table 5. The robustness of the influencing factors of the fertilizer use efficiency model is tested and presented in FUE(1) to FUE(4). The results show that the variables in different models have almost the same impact on fertilizer use efficiency, indicating that the model is strong and robust. Besides, the overall fit of the models as indicated by the log-likelihood statistics are all significant at the $1 \%$ significance level.

The results indicate that non-agricultural employment opportunity, apple planting area ratio, education, disaster ratio, fertilizer price, apple price and land size have greater impacts on fertilizer use efficiency than other factors. The climate factors have significant lower impacts on fertilizer use efficiency than other factors except irrigation fee, which has the lowest impacts on fertilizer use efficiency. While the fertilizer use efficiency has no 
Table 5

376 Estimated results of influencing factors of fertilizer use efficiency

\begin{tabular}{|c|c|c|c|c|c|c|c|c|c|c|}
\hline \multirow[t]{2}{*}{ Variables } & \multicolumn{2}{|l|}{ TE } & \multicolumn{2}{|l|}{ FUE(1) } & \multicolumn{2}{|l|}{ FUE(2) } & \multicolumn{2}{|l|}{ FUE(3) } & \multicolumn{2}{|l|}{ FUE(4) } \\
\hline & Coeff. & Std.Err & Coeff. & Std.Err & Coeff. & Std.Err & Coeff. & Std.Err & Coeff. & Std.Err \\
\hline \multicolumn{11}{|l|}{ Household characters } \\
\hline Education & -0.056 & 0.065 & 0.015 & 0.029 & $-0.319^{* *}$ & 0.141 & $-0.312^{* *}$ & 0.139 & $-0.338^{* *}$ & 0.134 \\
\hline Quadratic education & & & & & $0.021^{* *}$ & 0.009 & $0.021^{* *}$ & 0.009 & $0.023^{* * *}$ & 0.008 \\
\hline Income & 0.000 & 0.000 & 0.000 & 0.000 & 0.000 & 0.000 & & & & \\
\hline Irrigation fee & & & $0.002^{* * *}$ & 0.000 & $0.001^{* * *}$ & 0.000 & $0.001^{* * *}$ & 0.000 & $0.001^{* * *}$ & 0.000 \\
\hline Land size & & & 0.097 & 0.071 & $0.124^{*}$ & 0.070 & $0.121^{*}$ & 0.069 & 0.102 & 0.069 \\
\hline \multicolumn{11}{|c|}{ Natural environment and climate change } \\
\hline Disaster ratio & 0.294 & 0.207 & $-0.097^{*}$ & 0.058 & $-0.161^{*}$ & 0.086 & $-0.157^{*}$ & 0.084 & $-0.093^{*}$ & 0.057 \\
\hline Precipitation & $0.009^{* * *}$ & 0.004 & $-0.003^{*}$ & 0.002 & $-0.003^{*}$ & 0.002 & $-0.003^{*}$ & 0.002 & -0.002 & 0.002 \\
\hline Temperature & 0.031 & 0.051 & -0.009 & 0.021 & -0.005 & 0.021 & -0.005 & 0.021 & & \\
\hline Sunshine hours & 0.005 & 0.003 & $-0.004^{* * *}$ & 0.001 & $-0.003^{* *}$ & 0.001 & $-0.003^{* *}$ & 0.001 & $-0.003^{* *}$ & 0.001 \\
\hline \multicolumn{11}{|l|}{ Economic and social characters } \\
\hline Apple planting area ratio & $-2.310^{*}$ & 1.289 & $0.678^{* * *}$ & 0.234 & $0.655^{* * *}$ & 0.231 & $0.660^{* * *}$ & 0.232 & $0.672^{* * *}$ & 0.228 \\
\hline Financial ratio of agriculture & -0.045 & 0.498 & -0.042 & 0.158 & -0.056 & 0.153 & & & & \\
\hline Effective irrigation area ratio & -0.427 & 0.353 & & & 0.181 & 0.178 & 0.169 & 0.173 & & \\
\hline Fertilizer price & & & $0.106^{* * *}$ & 0.026 & $0.107^{* * *}$ & 0.025 & $0.107^{* * *}$ & 0.025 & $0.109^{* * *}$ & 0.024 \\
\hline Apple price & $0.123^{* *}$ & 0.059 & $-0.045^{* *}$ & 0.020 & $-0.046^{* *}$ & 0.020 & $-0.047^{* * *}$ & 0.017 & $-0.049^{* * *}$ & 0.016 \\
\hline $\begin{array}{l}\text { Non-agricultural employment } \\
\text { opportunity }\end{array}$ & $-1.642^{*}$ & 0.986 & $1.272^{* * *}$ & 0.433 & $1.569^{* * *}$ & 0.439 & $1.457^{* * *}$ & 0.342 & $1.529^{* * *}$ & 0.273 \\
\hline \multicolumn{11}{|l|}{ Dummies } \\
\hline Formula fertilizer & & & -0.008 & 0.058 & -0.018 & 0.057 & -0.010 & 0.054 & & \\
\hline Region & & & -0.097 & 0.087 & -0.060 & 0.093 & -0.056 & 0.091 & & \\
\hline Constant & -0.062 & 0.980 & 0.474 & 0.427 & $1.403^{* *}$ & 0.587 & $1.359^{* *}$ & 0.580 & $1.309^{* *}$ & 0.547 \\
\hline Log-likelihood & & & 60.595 & & 64.339 & & 64.223 & & 63.199 & \\
\hline Sample size & 184 & & 184 & & 184 & & 184 & & 184 & \\
\hline
\end{tabular}

$*, * *$ and $* * *$ represent the significance levels of $10 \%, 5 \%$ and $1 \%$, respectively

\section{5. Discussion}

\subsection{Spatial and temporal characteristics of fertilizer use efficiency}

Fertilizer use efficiency experiences an increasing trend over the research period, although unreasonable fertilizer use causes a loss of fertilizer use efficiency (Table 4). The average fertilizer use efficiency increases from 0.313 in 1992 to 0.591 in 2014, and the annual efficiency change is $2.935 \%$, exceeding the technical efficiency change. The increasing trend of fertilizer use efficiency is most obvious from 2001, with the annual rate of increase increasing to $4.037 \%$ since then. These results may be related to the increasing price of fertilizer and the implementation of the formula fertilizer project since 2005, leading farmers to reduce fertilizer input (Shi et al., 2015).

Significant variations of fertilizer use efficiencies in different provinces are also observed. The highest average fertilizer use efficiency is 0.684 in Shandong province from 1992-2014, followed by the provinces of Shanxi, Liaoning, and Shaanxi, with each province achieving average fertilizer use efficiency above 0.5 . In these provinces, the fertilizer use efficiencies have similar increasing trends, except Liaoning, which has an inverted U-shape. The provinces with lowest fertilizer use efficiencies are Henan and Gansu: Henan has an average efficiency of 
approximately 0.3 , and Gansu has the lowest efficiency at 0.239 . The fertilizer use efficiencies of the remaining provinces, such as Hebei and Ningxia, hover around the average efficiency level, approximately 0.44 . By region, the average fertilizer use efficiency in Bohai Bay in China is 0.555, which is higher than the Loess Plateau region with a value of 0.421 .

The results are very similar and have almost the same trend over time as the results of Yang and Han (2011) and Shi et al. (2015), and are opposite to the results of Swaney et al. (2018). Yang and Han (2011) finds that the average fertilizer use efficiencies of wheat and corn production in China from 1996-2009 are 0.474 and 0.452, respectively. Shi et al. (2015) estimates an average fertilizer use efficiency score of 0.45 for wheat production using the same major wheat production province data but for 1998-2013. Both studies find an increasing trend in fertilizer use efficiency over time. However, Swaney et al. (2018) indicate that nitrogen-use efficiency in US crops generally declines from 1987-2012, mainly because of increased use of mineral $\mathrm{N}$ fertilizer above crop $\mathrm{N}$ requirements. Additionally, average fertilizer use efficiency in apple production is $22 \%$ higher than in rice production in Taihu Basin (Ma et al., 2014) and 25.53\% lower than crop production in the United States (Swaney et al., 2018). Besides, efficiency in the Loess Plateau region is almost the same as the result of Zhang and Bai (2017), with fertilizer use efficiency of apple production at 0.43 in the Loess Plateau, estimated by the DEA model. Natural scientists researching the chemical fertilizer nitrogen (CF-N) use efficiency show similar levels of CF-N use efficiency for crop production in China, with results ranging from 0.28-0.41 (Zhu, 1997; Yang et al., 2016) and lower than in developed countries (Ladha et al., 2016; Swaney et al., 2018). All these results demonstrate that fertilizer use efficiency in China is very low; therefore, there is great potential for increasing producer incomes and reducing environmental pollution by improving fertilizer use efficiency.

\subsection{Analysis of factors influencing fertilizer use efficiency}

Among the household characteristic variables, a noteworthy finding is that education level has a significant negative impact on fertilizer use efficiency, and the effect of the educational quadratic has a significant positive impact, that is, the effect of education on fertilizer use efficiency has U-shape characteristics. This result suggests that the impact of education on fertilizer use efficiency has a threshold effect: An education level below or above the threshold will reduce or improve fertilizer use efficiency, respectively. The findings can be explained by the higher educational level enhancing the farmers' ability to use, absorb, and digest technology, which can improve technical efficiency and also increase the likeliness that they would accept and apply high-quality fertilizers or the early adoption of advanced fertilization techniques to improve fertilizer use efficiency (Ma et al., 2014). Educational level below this threshold in apple production may greatly diminish its effectiveness (Speelman et al., 2008). At present, the education level of primary middle school individuals in China is insufficient to improve the fertilizer use efficiency of apple production. This result is consistent with the result of Zhang and Bai (2017), who found that a lower education level has a negative impact on fertilizer use efficiency in apple production in the Loess Plateau. However, Wu et al. (2011) and Shi et al. (2015) have found that education had a positive impact on fertilizer use efficiency of grain crops. This result illustrates that education has different effects on fertilizer use efficiencies of cash and grain crops.

Irrigation fees have a small positive impact on fertilizer use efficiency, supporting the arguments of Ju et al. (2009), Kahrl et al. (2010), and Mahajan et al. (2012), that is, fertilizer use efficiency can be improved by the interaction of water and fertilizer. Land size positively influences fertilizer use efficiency, which means larger land size tends to be more efficient regarding fertilizer use, a result consistent with the literature (Wu, 2011; Wang et 
al., 2017). Fertilizer use efficiency is mainly improved by two approaches. One approach is to reduce the use of fertilizer for the same crop yields. Wu et al. (2018) indicated that a $1 \%$ increase in farm size is associated with a $0.3 \%$ decrease in fertilizer use but the crop yields remain the same. The other approach is the adoption of advanced technology (Sarkar et al., 2018). Farmers with a larger land size are more likely to use new technologies to increase production and efficiency (Speelman et al., 2008; Yang and Han, 2011).

Fertilizer use efficiency is negatively influenced by all natural environment and climate change factors. Disaster ratio has a significant negative effect on fertilizer use efficiency, a finding supported by Ma et al. (2014) and Quemada and Gabriel (2016). Farmers who have suffered natural disasters use more fertilizer to compensate for the negative effects of disasters on output, which is harmful to fertilizer use efficiency. Precipitation has a significant negative impact on technical and fertilizer use efficiencies, which is supported by Lamb (2003) and Naseem and Kelly (1999). They found that precipitation has a significant positive impact on fertilizer use intensity, and farmers generally increase fertilizer use in years of greater precipitation, and many of them use more than the optimal amount of fertilizer, which can result in low fertilizer use efficiency. Additionally, precipitation leads to a serious loss of fertilizer because of, for example, increased fertilizer penetration or runoff losses (Quemada and Gabriel, 2016). The impact of sunshine hours on fertilizer use efficiency is significantly negative. Long-term continuous sunshine hours can lead to drought and accelerated evaporation of fertilizers, which makes fertilizer use inefficient (Ju et al., 2009). Temperature also has non-significant negative impact on fertilizer use efficiency.

The apple planting area ratio of each province has a significant positive impact on technical and fertilizer use efficiencies. A higher apple planting area ratio means the government pays more attention to the apple industry and, consequently, more research and development funds are used to develop new technologies for apple production, and related policies to promote the development of the apple industry. Therefore, technical and fertilizer use efficiencies will improve accordingly. Fertilizer use efficiency is positively affected by fertilizer price, which has been directly supported by Shi et al. (2015), Wang (2017), and Zhang and Bai (2017). This result suggests that high fertilizer price is beneficial to fertilizer use efficiency, which has been indirectly proven by Lamb (2003), Abdoulaye and Sanders (2005), Stuart et al. (2014), and Nasrin et al. (2019). They have indicated that fertilizer prices have a negative impact on fertilizer use intensity in India, Niger, United States and Bangladesh, respectively, suggesting that the higher the fertilizer price, the less the fertilizer use, and the higher the efficiency of fertilizer use. A possible explanation for this phenomenon is that an increasing fertilizer price will force farmers to plan the amount of fertilizer use in various stages of apple cultivation and optimize the fertilization structure to minimize fertilizer input to save costs, which contributes to improving fertilizer use efficiency. Apple price has a significant negative impact on fertilizer use efficiency, indicating that a high apple price is harmful to fertilizer use efficiency. When apple prices are high, farmers use more fertilizer to obtain greater yield and greater income (Nasrin et al., 2019), which reduces fertilizer use efficiency.

Non-agricultural employment opportunities positively influence technical and fertilizer use efficiencies. This result indicates that the current large-scale agricultural labor transfer to off-farm industry can promote apple production and improve fertilizer use efficiency. These findings support the arguments of Ma et al. (2014). The increase in off-farm income through non-agricultural employment means that agricultural production is no longer the basis for farmers to survive. That is, on one hand, agriculture is not the first choice for farmers; thus, nonagricultural employment is substituting for agricultural activities. As a result, less fertilizer is used for apple production, which is beneficial for fertilizer use efficiency because of the previous overuse of fertilizer in apple 
production. On the other hand, high off-farm income will break the financial constraints of agricultural investment, and high-quality fertilizer will be used for apple production for food quality safety, which can improve fertilizer use efficiency. However, this result is indirectly inconsistent with the results of Lamb (2003) and Nasrin (2019), who have demonstrated the positive impact of non-agricultural employment on fertilizer use intensity in India and Bangladesh, indicating that more fertilizers will be used when there are more non-agricultural employment opportunities, resulting in low fertilizer use efficiency. This result is different from China: Farmers in China with more non-agricultural employment opportunities will use less fertilizer or high-quality fertilizer, which can improve fertilizer use efficiency. The differences may depend on the individual's living standards and the agricultural development stage of the research area. The agriculture production in China has transferred from food quantity safety to food quality safety, inducing less or high-quality fertilizer to be used, and individuals in India and Bangladesh are at the stage of pursuing food quantity safety, which results in more fertilizer used and lower fertilizer use efficiency.

The effect of formula fertilizer on fertilizer use efficiency is not significant, a result similar to that of Ma et al. (2014). The regional dummy variable does not significantly affect fertilizer use efficiency, which implies the difference in fertilizer use efficiency for two major apple production regions is not statistically significant. In addition, other variables with no statistically significant impact on fertilizer use efficiency are income, temperature, financial ratio of agriculture, and effective irrigation area ratio.

\subsection{Sensitivity analysis of fertilizer use efficiency}

To analyze the sensitivity of the fertilizer use efficiency to influencing factors, the average values of the influencing factors in Table 1 are supposed as a fixed datum. Based on the datum, the sensitivities of fertilizer use efficiency to changes in different influencing factors are calculated (Fig.2).

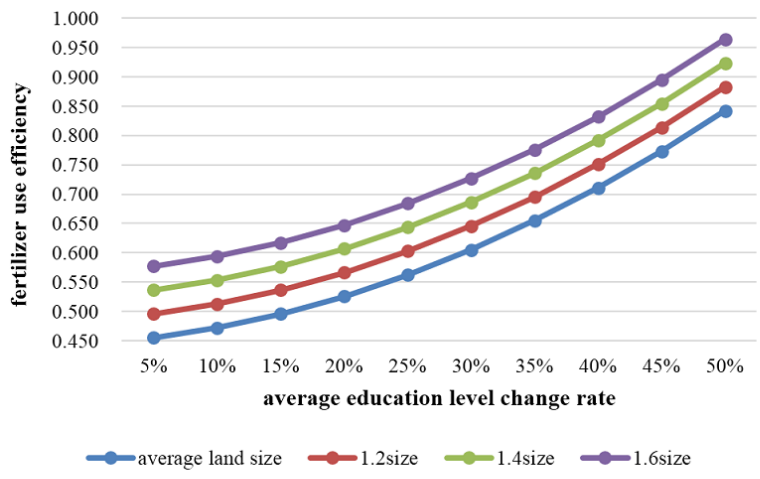

(a) The sensitivity of fertilizer use efficiency to education level change

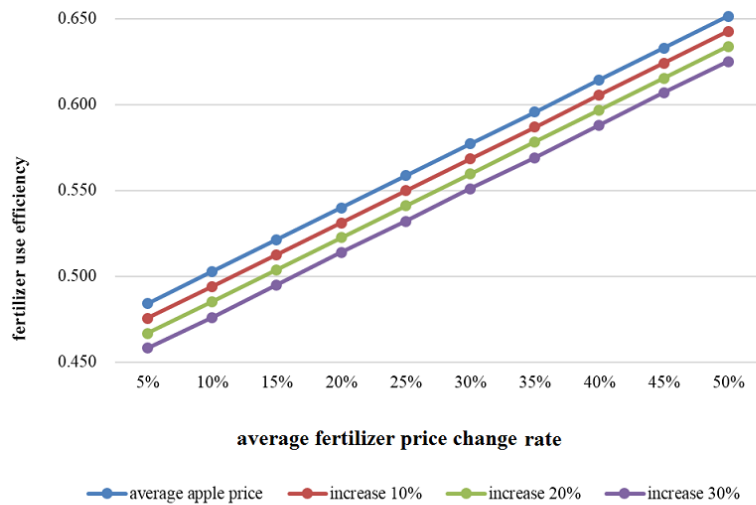

(c) The sensitivity of fertilizer use efficiency to fertilizer price change

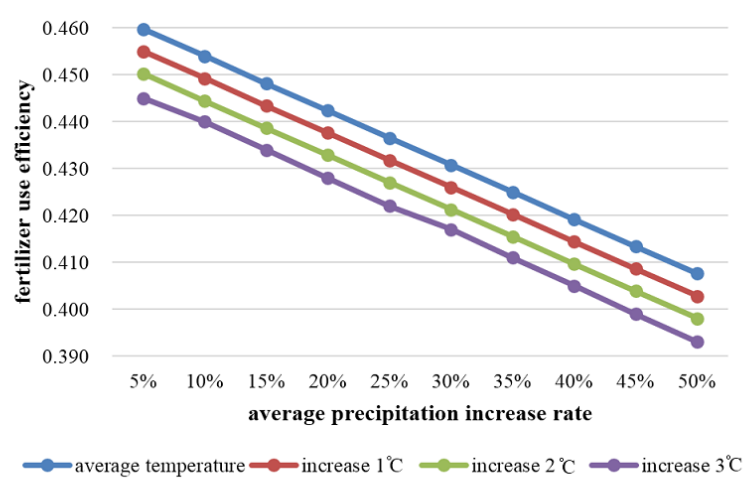

(b) The sensitivity of fertilizer use efficiency to precipitation change

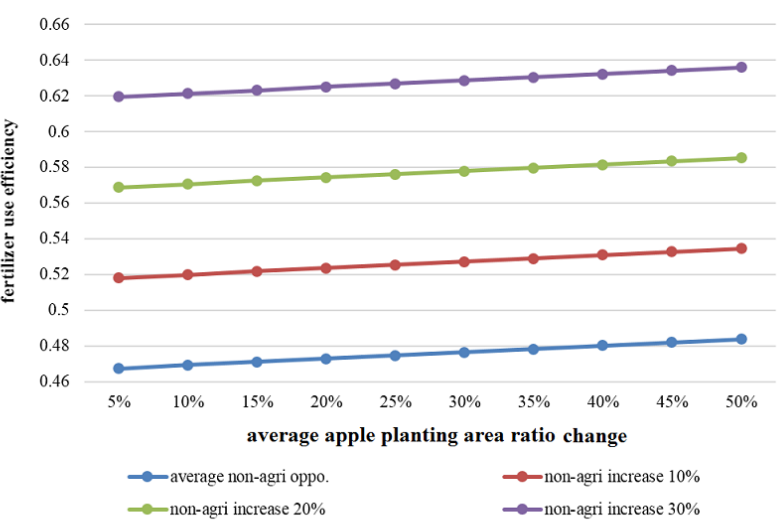

(d) The sensitivity of fertilizer use efficiency to apple planting area ratio change 
Fig. 2. the sensitivity of fertilizer use efficiency to changes in different influencing factors

In Fig. 2, fertilizer use efficiency has a quadric curve relationship with the education level change rate, and the relationships between fertilizer use efficiency and precipitation, and fertilizer price and apple planting area ratio change, are linear. Additionally, an observation is that education level change has the biggest impact on fertilizer use efficiency, followed by fertilizer price and precipitation change, and apple planting area ratio has the smallest impact on fertilizer use efficiency.

Specifically, Fig.2(a) shows that fertilizer use efficiency increases with the increases in education level and land size: When the education level increases by $50 \%$ and the land size expands to 1.6 times, the fertilizer use efficiency will increase to 0.964 from 0.472 . Thus, fertilizer use efficiency is sensitive to education level and land size. Further, compared with land size, fertilizer use efficiency is more sensitive to changes in educational levels. Fig.2(b) reveals that fertilizer use efficiency declines slightly with the increasing precipitation change and temperature; thus, fertilizer use efficiency is weakly sensitive to the change in precipitation and temperature. Fig.2(c) reflects that fertilizer use efficiency increases with increases in the fertilizer price under ceteris paribus, while fertilizer use efficiency decreases with the increases in the apple price; additionally, compared with apple price, fertilizer use efficiency is more sensitive to fertilizer price. Fig.2(d) shows that fertilizer use efficiency increases with increases in the apple planting area ratio and non-agricultural employment opportunity, and nonagricultural employment opportunity has a bigger impact on fertilizer use efficiency than apple planting area ratio but less than education level and fertilizer price. To sum up, fertilizer use efficiencies are more sensitive to education level and fertilizer price than non-agricultural employment opportunity and land size, and it is weakly sensitive to the change in climate factors, apple price, and apple planting area ratio, and the factors with high sensitivity should receive more attention.

\section{Conclusions and implications}

In this paper, a stochastic frontier translog production function was estimated using apple production and local climate panel data of eight major apple production provinces in China from 1992-2014. The estimates were used to assess technical and fertilizer use efficiencies in apple production. In addition, factors influencing fertilizer use efficiency were investigated using a panel random-effects Tobit model, and the sensitivities analysis considering changes in the influencing factors were discussed. The results suggested key entry points to reduce chemical fertilizer use and improve fertilizer use efficiency in apple production and have implications for making decisions concerning environmental protection policies.

(1) The empirical results showed that the average technical efficiency of apple production was 0.868 , indicating a 13.2\% scope for increasing apple output with the existing inputs. In addition, fertilizer use efficiency ranged from $0.002-0.878$, which was much lower and had greater variation than technical efficiency, which ranged from $0.745-0.938$. The average fertilizer use efficiency was 0.472 , indicating that fertilizer input could be reduced by $52.8 \%$ while maintaining apple output with current technologies and inputs.

(2) Promoting non-agricultural employment opportunities and land circulation may be key entry points to improve fertilizer use efficiency. Because of the positive impacts of non-agricultural employment opportunities and land size on fertilizer use efficiency and its higher sensitivity to them, the government should pay more attention to policies that promote the transformation of rural labor to non-agricultural industries and rural land circulation for larger farm size, which may increase fertilizer use efficiency and income. 

impact of fertilizer price on fertilizer use efficiency and its high sensitivity to fertilizer price, controlling the increase in fertilizer prices may be detrimental to solving the problem of fertilizer non-point source pollution because of large amounts of fertilizer used and the overstocking of fertilizer. Therefore, the government should consider reducing the non-point source pollution of fertilizer when formulating a subsidy policy to address fertilizer price and enhancing the flexibility of the fertilizer price regulatory mechanism, such as the different fertilizer price policies for different fertilizer varieties, and guiding and encouraging farmers to buy and use controlled-release and eco-friendly fertilizers.

(4) Strengthening and expanding rural extension services are also important factors to increase fertilizer use efficiency. The education level of farmers has a significant impact on fertilizer use efficiency, which means more training should focus on encouraging farmers to change their old production methods and adopt new methods in the appropriate manner, such as substituting the method of broadcast application with furrow or dibble fertilizer application, which can reduce fertilizer losses, increase fertilizer use efficiency, and narrow the gap between technology and skill. Additionally, the government should raise farmers' environmental protection awareness, and encourage them to use more organic and formula fertilizers. The implications are supported by, conclusions of Naseem and Kelly (1999), Stuart et al. (2014) and Nasrin et al. (2019), who have indicated that rural extension services and the higher education level of farmers can promote the adoption of new technologies for saving fertilizer in sub-Saharan Africa, the United States and Bangladesh, respectively.

(5) Finally, improving irrigation techniques and rainfall use efficiency may be another entry point to increase fertilizer use efficiency. The popular method of flood irrigation can lead to chemical fertilizer flowing into rivers and underground water systems and low fertilizer use efficiency. Advanced irrigation techniques such as drip irrigation, sprinkler irrigation, and water-fertilizer integration can reduce the losses of chemical fertilizer and improve fertilizer use efficiency. Additionally, rainfall use efficiency can be increased by improving infrastructure such as water cellars for collecting rainfall, especially in arid and semi-arid regions such as the Loess Plateau region in China, where farmers often must manage severe shortages of water.

The conclusion has provided a relevant reference for the government to improve fertilizer use efficiency in China, and from the discussion, the following summary can be posed: Almost all of the results are applicable to countries all over the world, including developing and developed countries, and the only controversial topic is the effect of non-agricultural employment opportunities on fertilizer use efficiency, which depends on the development stage of the research area, if at the stage of pursuing food quality and sustainable safety, chemical fertilizer may be used less or replaced by high-quality or organic fertilizer, which has positive impact on fertilizer use efficiency; at the stage of food quantity safety for living, more fertilizer may be used and results in low fertilizer use efficiency. Thus, some conditions should be considered for transferability of the results to other continents. Notably, the research is preliminary. For example, the research mainly focuses on apple industry in

567 China. Further research should pay more attention to the comparison of fertilizer use efficiency in different countries.

\section{Acknowledgements}

The study was supported by the National Natural Science Foundation of China (71303188), National Key 

provided by the anonymous referees which significantly improved the quality of this paper.

\section{References}

Abay, C., Miran, B., Gunden, C., 2004. An analysis of input use efficiency in tobacco production with respect to sustainability: the case study of Turkey. J. Sustain. Agr. 24(3), 123-143.

Abdoulaye, T., Sandrs, J., 2005. Stages and determinants of fertilizer use in semiarid African agriculture: the Niger experience. Agri. Econ. $32,167-179$

Aguilera, E., Lassaletta, L., Gattinger, A., Gimeno, B., 2013. Managing soil carbon for climate change mitigation and adaptation in Mediterranean cropping systems. A meta-analysis. Agr. Ecosyst. Environ. 168(1755), 25-36.

Asai, M., Reidsma, P., Feng, S., 2010. Impacts of agricultural land use changes on biodiversity in Taihu Lake Basin, China: a multi-scale cause-effect approach considering multiple land use functions. Inter. J. Biodi. Sci. Ecosys. Serv. Manage. 6(3-4), 119-130.

Bai, X., Li, J., Zheng, S., 2012. Empirical analysis of partial technical progress, output elasticity and productivity in apple industry. Sta. Decis. 21,114-118.

Bai, X., Chen, X., Huo, X., 2015. The impact of climate change on apple output and total factor productivity in major apple production provinces. Agrot. Econ. 8, 98-111.

Battese, G.E., Coelli, T.J., 1995. A model for technical inefficiency effects in a stochastic frontier production function for panel data. Empiri. Econ. 20, 325-332.

Chen, J., Cao, F., Xiong, H., Huang, M., Zou, Y.,Xiong, Y., 2017. Effects of single basal application of coated compound fertilizer on yield and nitrogen use efficiency in double-cropped rice. Crop J. 5(3), 265-270.

Coelli, T.J., 1995. Recent developments in frontier modelling and efficiency measurement. Aus. J. Agr. Econ. 39 (3), 219-245.

Domagalski, J., Lin, C., Luo, Y., Kang, J., Munn, M., 2007. Eutrophication study at the Panjiakou-Daheiting Reservoir system, Northern Hebei Province, People's Republic of China: chlorophyII-a model and sources of phosphorus and nitrogen. Agr. Water Manage. 94(13), 43-53.

FAO, 2017. FAOSTAT: FAO Statistical Databases (Rome, Italy). http://www.fao.org/faostat/en/\#data/QC.

Guo, J.H., Liu, X.J., Zhang, Y., Shen, J.L., Han, W.X., Zhang, W.F., Christie, P., Goulding, K.W.T., Vitousek, P.M., Zhang, F.S., 2010. Significant acidification in Major Chinese Croplands. Science 327(5968), 1008-1010.

Gutierrez, E., Aguilera, E., Lozano, S., Guzman, G., 2017. A two-stage DEA approach for quantifying and analysing the inefficiency of conventional and organic rain-fed cereals in Spain. J. Clean. Prod. 149, 335-348.

Ju, X., Xing, G., Chen, X., Zhang, S., Zhang, L., Liu, X., Cui, Z., Yin, B., Christie, P., Zhu, Z., Tilman, G., 2009. Reducing environmental risk by improving N management in intensive Chinese agricultural systems. Proc. Natl. Acad. Sci. U S A 106(9), 3041-3046.

Kahrl, F., Li, Y., Su, Y., Tennigkeit, T., Wilkes, A., Xu, J., 2010. Greenhouse gas emissions from nitrogen fertilizer use in China. Environ. Sci. policy 13(8), 688-694.

Krupnik T.J., Six J., Ladha J.K., Paine, M.J., Van, K.C., 2004. An assessment of fertilizer nitrogen recovery efficiency by grain crops. In: Mosier, A.R., Syers, J.K., Freney, J.R. (Eds.), Agriculture and nitrogen cycle. Island Press, Washington, D.C., pp. 193-207.

Ladha, J.K., Chakraborty, D., 2016. Nitrogen and cereal production: opportunities for enhanced efficiency and reduced N losses. In: Proceedings of the 2016 International Nitrogen Initiative Conference, Solutions to Improve Nitrogen Use Efficiency for the World, 4-8 December 2016, Melbourne, Australia.

Lassaletta, L., Billen, G., Grizzetti, B., Anglade, J., Garnier, J., 2014. 50 year trends in nitrogen use efficiency of world cropping systems: the relationship between yield and nitrogen input to cropland. Environ. Resour. Lett. 9(10), 105011.

Lamb, R., 2003. Fertilizer use, risk, and off-farm labor markets in the semi-arid tropics of India. Am. J. Agr. Econ. 85 (2), 359-371.

Liu, D., Li, Q., Song, X., 2017. Analysis on fertilizer application efficiency of grain production in China. Res. Deve. Mark. 33(4), 401-407.

Ma, L., Feng S., Reidsma, P., Qu, F., Heerink, N., 2014. Identifying entry points to improve fertilizer use efficiency in Taihu Basin, China. Land Use Policy 37(2), 52-59.

Malano, H., Burton, M., Makin, I., 2004. Benchmarking performance in the irrigation and drainage sector: a tool for change. Irrig. Drain. 53(2), 119-133.

Mahajan, G., Chauhan, B.S., Timsina, J., Singh, P.P., Singh, K., 2012. Crop performance and water- and nitrogen-use efficiencies in dryseeded rice in response to irrigation and fertilizer amounts in northwest India. Field Crop Res. 134(3), 59-70. 
Marcela, C.L., Jorge, M., Cornelia, R., Leo, M.C., Marcela, H., Marc, D., Maria, L.M., 2018. Smart fertilizers as a strategy for sustainable agriculture. Adv. Agron. 147(1), 119-157.

Nasrin, M., Bauer, S., Arman, M. 2019. Dataset on measuring perception about fertilizer subsidy policy and factors behind differential farm level fertilizer usage in Bangladesh. Data in Brief 22, 851-858.

National Bureau of Statistics of China (NBSC), 1993-2015a. China Statistical Yearbooks. China's Statistical Press, Beijing, China. National Bureau of Statistics of China (NBSC), 1993-2015b. China rural Statistical Yearbooks. China's Statistical Press, Beijing, China. National Development and Reform Commission of China(NDRC), 1993-2015. China Agricultural Product Cost-Benefit Compilation. China's Statistical Press, Beijing, China.

Naseem, A., Kelly, V. 1999. Macro trends and determinants of fertilizer use In Sub-Saharan Africa. MSU International Development Working Paper, No.73. https://ageconsearch.umn.edu/record/54671/files/idwp73.pdf

Oude Lansink, A., Silva, E., 2004. Non-parametric production analysis of pesticides use in the Netherlands. J. Produc. Analy. 21(1), 49-65.

Quemada, M., Gabriel, J.L., 2016. Approaches for increasing nitrogen and water use efficiency simultaneously. Glob. Food Secur. 9, $29-35$.

Reinhard, S., Lovell, C.A.K., Thijssen, G., 1999. Econometric estimation of technical and environmental efficiency: an application to dutch dairy farms. Am. J. Agr. Econ. 81(1), 44-66.

Rodriguez Diaz, J.A., Camacho Poyato, E., Lopez Luque, R., 2004. Application of data envelopment analysis to studies of irrigation efficiency in Analusia. J. Irrig. Drain. E. 130(3), 175-183.

Salvo, M., Raffaelli, R., Moser, R., 2013. The impact of climate change on permanent crops in an Alpine region: A Ricardian analysis. Agr. Syst. 118(2), 23-32.

Sarkar, A., Biswas, D.R., Datta, S.C., Roy, T., Moharana, P.C., Biswas, S.S., Ghosh, A., 2018 .Polymer coated novel controlled release rock phosphate formulations for improving phosphorus use efficiency by wheat in an Inceptisol. Soil Till. Res. 180, 48-62.

Shaviv, A., 2001. Advances in controlled release fertilizers. Adv. Agron. 71(01), 1-49.

Shi, J., Zhu, J., Luan, J., 2015. Fertilizer use efficiency of wheat production in China and its determinants. Agrot. Econ. 11, 69-78.

Singbo, A.G., Oude Lansink, A., Emvalomatis, G., 2015. Estimating shadow prices and efficiency analysis of productive inputs and pesticide use of vegetable production. Eur. J. Oper. Res. 245(1), 265-272.

Speelman,S., Haese, M., Buysse, J., Hases, L., 2008. A measure for the efficiency of water use and its determinants, a case study of smallscale irrigation schemes in North-West Province, South Africa. Agr. Syst. 98(1), 31-39.

Stuare, D., Schewe, R., McDermott, M., 2014. Reducing nitrogen fertilizer application as a climate change mitigation strategy: Understanding farmer decision-making and potential barriers to change in the US. Land use Policy 36, 210-218.

Wang, S., Liu, Y., Tian, X., Yan, B., 2017. The Estimation of Fertilizer Use Efficiency in Agriculture and the Improving Ways. Environ. Econ. Res. 3, 101-114.

Wang, Y., Chen, W., Kang, Y., Li, W., Guo, F., 2018. Spatial correlation of factors affecting $\mathrm{CO}_{2}$ emission at provincial level in China: a geographically weighted regression approach. J. Clean. Prod. 184, 929-937.

Wu, Y., 2011. Chemical fertilizer use efficiency and its determinants in China's farming sector. China Agr. Econ. Rev. 3(2), 117-130.

Wu, Y., Xi, X., Tang, X., Luo, D., Gu, B., Lam, S., Vitousek, P., Chen, D., 2018. Policy distortions, farm size, and the overuse of agricultural chemicals in China. Proc. Natl. Acad. Sci. U S A 115(27), 7010-7015.

Yang, X., Geng, J., Li, C., Zhang, M., Chen, B., Tian, X., Zheng, W., Liu, Z., Wang, C., 2016. Combined application of polymer coated potassium chloride and urea improved fertilizer use efficiencies, yield and leaf photosynthesis of cotton on saline soil. Field Crop Res. 197(8), 63-73.

Yang, Z., Han, H., 2011. Technical efficiency of fertilizer and its influencing factors: based on wheat and corn empirical study. J. China Agr. Univ. 16(1), 140-147.

Zhang, B., Bai, X., 2017. Fertilizer use efficiency and its affecting factors in apple production in Loess Plateau. J. Arid Land Res. Environ. 31(11), 55-61.

Zhang, D., Li, W., Xin, C., Tang, W., Eneji, A., Dong, H., 2012. Lint yield and nitrogen use efficiency of field-grown cotton vary with soil salinity and nitrogen application rate. Field Crop Res. 138(3), 63-70.

Zhang, W., Tian, Z., Zhang, N., Li, X., 1996. Nitrate pollution of groundwater in northern China. Agr. Ecosyst. Environ. 59(3), 223-231.

Zhou, Y., Zhang, X., Xu, T., Geng, X., Zhang, P., Yan, B., 2015. Technical and environmental efficiency of hog production in china-a stochastic frontier production function analysis. J. Integ. Agr. 14(6), 1069-1080.

Zhu Z., 1997. Fate and management of fertilizer nitrogen in agro-ecosystems. In: Zhu Z., Wen Q., Freney J.R. (eds.), Nitrogen in Soils of China. Kluwer Academic Publishers, Dordrecht, The Netherlands, pp. 239-279. 

management strategies. Nutr. Cycl. Agroecosys. 63(2-3), 117-127. 